\title{
Raising Awareness on Sustainability Issues through a Mobile Game
}

\begin{abstract}
The paper presents a review on, and analysis of, the design, development and evaluation of experiences of learning through the 'Sustainability Serious Game'. The mobile game has been developed as means of helping public authorities to collect information and feedback on how public spaces could be improved based on collective intelligence procedures. Furthermore, as part of enhancing learning, the game intends to provide knowledge and awareness on sustainability issues for public constructions relevant to engineering and architectural disciplines. Deployed targeted questionnaires with thirty-three (33) computer science students in UK and analysed through a Likert Scale findings from evaluation demonstrate that a conceptual change may be achieved in relation to how sustainability has been perceived. A questionnaire with 20 questions was distributed to students for evaluating various elements of the game such as usability characteristics, accumulation, assimilation and consolidation of new knowledge patterns related to the learning-oriented benefits of the game with an implicit focus on whether the game can be integrated within an academic setting. The fundamental conclusion from the analysis of the game uptake is that it enhances student's engagement with sustainability issues, especially in blended learning contexts for 'blending' different pedagogical approaches with game-oriented features as means of improving educational practice.
\end{abstract}

Keywords: mobile serious games; sustainability; public spaces, urban cities

\section{INTRODUCTION}

Promoting learning through public participation is key element in raising awareness regarding the sustainability of open public spaces among university students and professionals (e.g. engineers, architects, planners and public authorities). Traditionally, sustainability issues for urban cities are predominantly addressed through decisions and actions performed by local authorities in consultation with experts in designing, implementing and sustaining public constructions. It is, therefore, essential that tools are developed which support students in learning issues, policies and practices in designing and sustaining public spaces in collaboration with specialists in the field. The outcome of this is twofold: Firstly students are able to enhance their knowledge on sustainability issues through applying and transferring content knowledge in real world contexts; and secondly a direct contribution is achieved towards improving a designated public space.
From a European perspective, the sustainable city debate is increasing, featuring as a prominent issue in several policy documents of the European Commission such as the EU thematic strategy on Urban development [1] and the report of the BioRegional Development Group and the Commission for Architecture and the Build Environment (2008) of "What Makes an Ecotown'[2]. Since the purpose of the planning system is to contribute to sustainable development as means of addressing the linked challenges of climate change, resource use, economic prosperity and social well-being, the creation of links and relationships between students and professionals may allow the communal implementation of sustainable design and construction at the scale of open sites and parks in urban areas. Sustainable design and construction takes into account the resources used in construction as well as the environmental, social and economic impacts of the construction process itself, and how buildings are designed and used. Such European policies and guidelines aim to contribute to the enhancement of sustainability in three overarching ways: (1) elaborating further the issue of sustainable cities with special focus on public open spaces, whilst taking into account the views of professional planners and architects; (2) enhancing learning about sustainability among university students and (3) promoting the active involvement of students in planning and urban design for public spaces such as parks. This brings to the fore the emerging theme of improving local governance standards by involving students and other citizens in local decision making for promoting local democracy and community cohesion.

Such approaches draw on collaborative processes and practices to broaden existing sustainability designs and construction principles through participatory and studentcentred approaches to learning, which allow students to experience the process of planning and constructing urban spaces in a technologically-rich way. Although traditional methods of sustainable design and construction principally involve face-to-face interaction between the parties involved, technology-based interventions may exploit blended approaches, reducing the need for such interactions.

The movement towards the use of serious games as learning tools has proliferated as a result of the perception that such games can help to create a memorable and engaging learning experience. Various commentators and practitioners alike argue that serious games may develop and reinforce $21^{\text {st }}$ century skills such as collaboration, problemsolving and communication ([3] [4]). While in the past, teachers have been reluctant to use serious games for improving their teaching practice, there is an increasing 
interest, especially in science disciplines, to explore how serious games may be used change a belief, a perception or a feeling. The overarching assumption made is that serious games are built on sound learning principles encompassing teaching approaches that support the design of authentic and situated learning activities in an engaging and immersive way, although this is not always necessarily the case.

The paper explores the use of a mobile serious game to address these issues, which predominantly focuses upon promoting awareness whilst raising interest among students and professionals in the evaluation of sustainability as part of improving the quality of life in urban cities. In the following section, the state-of-the-art in serious games is linked to the issue of teaching and learning about sustainability in urban cities, leading to the description of the 'Sustainability Game' approach in Section 3. An analysis of the game in terms of user engagement and its potential to be used in an academic setting is then provided in Section 4. The results analysed were obtained by eliciting players' experiences of playing the game through 20 semi-structured questions, in a smallscale survey carried out during 2 piloting workshops. The overarching conclusion from the analysis of the user engagement and efficacy of the game for use as a learning tool within an academic setting is that the game may enhance student's engagement on sustainability issues, especially in blended learning contexts for 'blending' different pedagogical approaches with tools and media as means of transforming the educational practice. Moreover, students views on integrating the serious game as part of the curriculum may scaffold the process of acquiring knowledge as well as gaining previous cognitive schemata related to sustainability.

\section{BACKROUND}

The Commission for Architecture and the Built Environment $\mathrm{CABE}$ [1] principally promotes the importance of urban design and has a central tenet to incorporate the principles of sustainable development into all aspects of urban design and planning. The quality of public spaces plays a major role in the economic, social and environmental sustainability of our cities. The benefits of well-designed and managed public-space include encouraging social interaction and community cohesion as well as a more outdoor lifestyle, reducing stress levels and adapting to a change climate [1]. In line to this, public spaces are vital assets that would need to be designed and managed more flexibly in future. Local authorities may improve the quality of public spaces by developing public realm strategies, appointing public space champions and regenerating streets as active and comfortable spaces.

CABE's report focusing on ordinary places argues that while city centres have improved beyond recognition over the past ten years, many ordinary places stiff suffer from inefficient commercial development. Compulsory training in public participation for architects, planners and other build environment professionals seems to be important for creating a sense of participation and collaboration with the wider community. The report also recommends teaching all young people is a key strategy for being able to articulate what they think about a place, how it works and what would make it better. In CABE argue that in order to achieve a conceptual and realistic change on how public spaces are being planned and constructed, universities need to address sustainability issues more constructively in order for students to consolidate all the various processes and practices.

\section{A. Games for learning}

The 2013 NMC Horizon Report [5] asserts that games are effective tools for increasing student's motivation and engagement by involving them into a memorable learning experience. A serious game can be defined as "a game in which education (in its various forms) is the primary goal, rather than entertainment" [4] p.21. Zyda [6] suggested the element of developing game-mechanics of competition when the user plays against the computer in accordance to specific rules for encouraging immersion and engagement in a controlled environment. A study carried out by Ferreira et al., [7] sought to identify the possible relationships between the ability to identify mathematical patterns and the ability to play games with certain rules and victory conditions. The study showed that students were able to identify mathematical patterns more effectively by playing a game in comparison to traditional face-to-face teaching practices. Furthermore, concept scaffolding and simulation of real world experiences may be triggered effectively in order to solve problems and enhance student's performance. For example, [8] surveyed 264 students playing an online educational game and found a relationship between rewards and motives. [9] have shown that games can support novel approaches to learning by scaffolding players' experiences in new worlds and learn by trying to solve ill-defined problems inside the game, bringing to the fore the notion of 'learning by doing', which whilst not a new concept does seem to be increasingly important in the design of effective pedagogic games.

In recent years different aspects of serious games have been widely discussed including their impact and outcomes ([9]. [10]), motivating features [11] and in-game learning design [12]. This has led to an assumption that games might provide an environment where learning and teaching becomes engaging, memorable and fun [13]. Further, Hwang \& Sung [14] argued that pedagogically-driven games reflect strong commitment to educational values and have great potential to drive students in achieving intended learning outcomes.

\section{B. Frameworks for games}

Identifying the appropriate pedagogical approach and aligning it to an intended learning outcome specified by the teacher may determine what kind of learning processes, scaffolds and activities a particular type of game will afford. However, it is also notable that focusing on scaffolding and outcomes already introduces behavioral notions of learning rather than ones from the field of critical pedagogy. Thus, training teachers to adopt pedagogical approaches based on certain learning outcomes that are supported by different types of games may enhance their educational value. From a pragmatist perspective, however, this does not mean that 
certain pedagogies are more cohesive than others as this always depends on the complex interplay between the learning environment, the level of students and the learning situation the teacher aims to introduce. Yet there does need to be sound match been the learning philosophy and pedagogy of the game itself.

Different frameworks have been designed and deployed for serious games. These frameworks have been deployed for helping practitioners to identify and understand the learning features that need to be included as well as how these may be instantiated in conjunction to game mechanics especially for conceptualising and using a serious game as a tool for conducting research and as an intervention for learning how to do research. An example of a serious games framework is the EMERGO methodology (Nadolski et al., 2008) as means to guide the development of scenario-based games. The scenario idea stage is for learning designers and game developers to consider broad issues for the creation of the game-scenario. Specific questions are formed surrounding issues of purpose (e.g. why the game scenario is needed?); identification of target groups (Who is going to use the game scenario?); learning objectives (What are the learning objectives and intended learning outcomes?) for galvanising the design of the game. In addition, identifying barriers and challenges in developing the game is identified because it is an important task to be realised in this phase. The scenario design stage describes certain activities that students engage within the game. In the development scenario stage, the actual development of the game is realised. In the Scenario integration stage: During this phase, teachers, students and their roles are integrated into the game. Access rights are also considered to this stage and an elaboration of particular components and functionality is realized. Finally, The evaluation stage: Evaluation assesses whether the case fulfils the initial requirements defined during analysis.

\section{THE SUSTAINABILITY GAME}

The game contains an overall mission, focusing on public participation and negotiation, which is structured into quests, implemented by short, simple mini-games (Figure 1). Through the mini-games the player gets introduced to the process of urban planning, the design of sustainable spaces and the participation of citizens in this process. The game is predominantly available on the Web but it can also be played via a mobile phone. The game is available in 7 languages including Hungarian, Italian, Spanish, Dutch, English, Greek and Estonian. For the Web version, the game runs on any Web browser and users need to install Adobe Shockwave and the Adobe Flash Player plug in. A video tutorial has also been created for helping first time players to get familiarized with the environment, rules, goals, controls and overall game play. A cartoon presentation of the game is also available explaining the aim and scope translated into a mission for introducing the concept of sustainability practiced collectively between local citizens, public authorities, architects and engineers as means to improve urban design. The mobile version is available on android devices and it resembles the same features and mission as the web-based version.

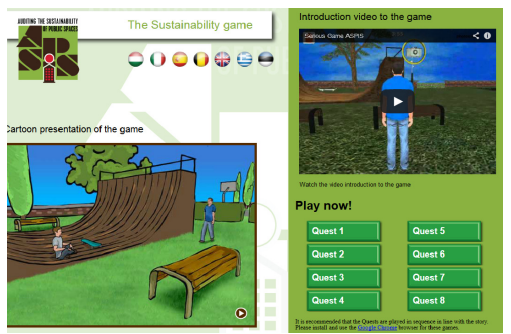

Figure 1. The Sustainability game structured into 8 quests implemented as mini games

The player steps into the role of Peter - a first year architecture student, who turns to his professor for help in solving the problem of his brother Larry. The decision to demolish the skating wall in the public park appeared to be only a small part of a bigger problem. Seeing Peter's interest and passion towards this cause, Professor McNutty challenges him to get involved in the redesign of the public park and offers to guide him through a series of short quests leading to the final goal which is to pitch the idea to the City Council. Each quest is presented to the player from McNutty in the form of an email screen-shot addressed to Peter. The aim of the first quest is for the player to understand needs of multiple users and identify park user groups.

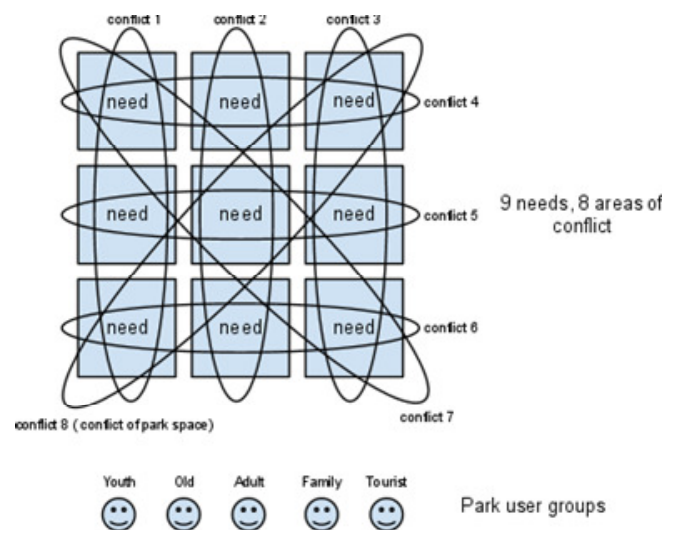

Figure 2. Nine needs to be arranged to give rise to eight areas of conflict

In the second quest, the player meets various people in the park for extracting information as a way of collecting as many correct suggestions as possible within a given time and matches them with the needs that have been collected in quest 1 . In the third quest the player's goal is to identify problems related to the current state of the park by clicking on pictures and classifying them under the correct category in the inventory. In the fourth quest, the player is directing as many people as possible by offering flyers for launching voluntary maintenance schemes for planting trees and cleaning the park. In the fifth quest the player"s goal is to raise awareness around the design of sustainable spaces and recruit more park users by collecting their signatures. In the 
sixth quest, the player selects the top three needs that must be realized in order to satisfy maximum park users. A 3 by 3 matrix puzzle is developed in which each square represents a particular need. The player must arrange the squares such that each line in the matrix lines up to reveal one area of conflict.

\section{METHOD}

This section provides an overarching analysis of the game questionnaire that was provided to computer science students, during 2 workshops organised in Coventry, as means of understanding their experiences, approaches and overall evaluation of the 'Sustainability Game'. The findings suggest that the game is more akin to be used for educational purposes as it enhances content and process related knowledge with regards to sustainability hence it encompasses pedagogically-rich elements which afford the alignment between teaching and learning strategies, assessment methods and learning goals. The evaluation was implemented with undergraduate (UG), postgraduate (PG) and doctoral students $(\mathrm{n}=33)$ studying computer science at Coventry University, UK (see Table 1). Students completed a small-scale questionnaire with 20 questions for evaluating various features of the game such as usability characteristics, accumulation assimilation and consolidation of new knowledge patterns related to the subject-based features of the game.

TABLE I. CONTEXTUAL ELEMENTS OF THE SUSTAINABILITY GAME EVALUATION

\begin{tabular}{cc}
\hline Contextual elements & Description \\
\hline Country & Coventry, United Kingdom \\
Place of the event & $\begin{array}{c}\text { Serious Games Institute, } \\
\text { Coventry University }\end{array}$ \\
Date & 26 April 2012; 14 \\
& September 2012 \\
Target group & UG, PG and PhD students \\
Number of participants & $23(26$ April); $10(14$ Sept $)$ \\
& $n=33$ \\
\hline
\end{tabular}

Against this background, a brief presentation was provided to students with the propensity of introducing the scope of playing the game as well as the adoption of the game-based learning approach in enacting sustainability in an open and collaborative way. Furthermore, an overarching demonstration of the game aided to immediately grasp basic functionality, as all students were familiar with computerbased environments and simulation tools and especially in the development and use of games for educational purposes. Students used the game through laptop and desktop computers installed in a dedicated state-of-the-art facility especially designed for educational related purposes with large screen panels and immersive learning spaces for collaborative and game-based learning. Students then completed the questionnaires informed by their experiences and actions of using the game. The game assessment has been relaised in two phases. During the first phase, 26 students played and evaluated the game and during the second phase 23 students played and evaluated the game.

\section{DISCUSSION OF RESULTS}

From the summary of the questionnaires, it seems that computer science students tend to perceive the game as intuitive, fun and immersive for understanding an array of aspects and issues of sustainability beyond traditional faceto-face teaching. This is advocated through the question that asked to students whether their knowledge has been improved after playing the game (see figure 3). It was clear from students' responses that their knowledge has been improved through personal construction of meaning resulting from their interactions with the virtual environment (see figure 3). From this perspective students experienced that different cognitive patterns of sustainability could be made explicit through the game and thus it created opportunities to explore sustainability ideas and test their robustness in explaining relevant phenomena, accounting for events and making predictions. Although, however, most of the students reported that they did not have any prior experiences in sustainability and ways of improving it through public consultation and co-creation of ideas, they felt that fragmented information gained on sustainability issues mainly informed through discussions with family and friends helped them to understand basic meanings and to transform them to cohesive information that could be consolidated and assimilated to knowledge. Students also highlighted the feature of listening, considering and understanding other peoples' views on sustainability, which seemed to be of a paramount importance for valuing other's people needs and circumstances. For example, they felt that the dialogue between them and the different avatars within the game created a dialogical process that recognised awareness, knowledge and understanding are constructed when individuals engage socially in discussions and activities about shared tasks and problems. This observation open a window for studying and exploring particular forms of collaboration in games (between physical and virtual characters) that may support students in gradually mastering some of the practices and norms that characterise collaborative knowledge creation within games. Recognising that the students have constructed their current understandings from their previous experiences, they felt that their knowledge was usefully related while playing the game. This may imply that the game allowed students to apply their knowledge to new contexts, through which students may generate new questions and new investigations and thereby transfer of learning may occur (see Figure 3 ). 
Students stated that the level of human-computer interaction was in a satisfactory level and natural promoting a sense of developing a virtual community between them and the virtual characters; while through gathering an interpreting their requirements (mainly in the $1^{\text {st }}$ and $2^{\text {nd }}$ quest) they could work together to address the different challenges. Furthermore, students felt that the game was immersive enough to keep them interested throughout the quests although some additions and/or improvements might be necessary in the richness of the animations or around the area outside the park which does not have many events and/or interactions to explore.

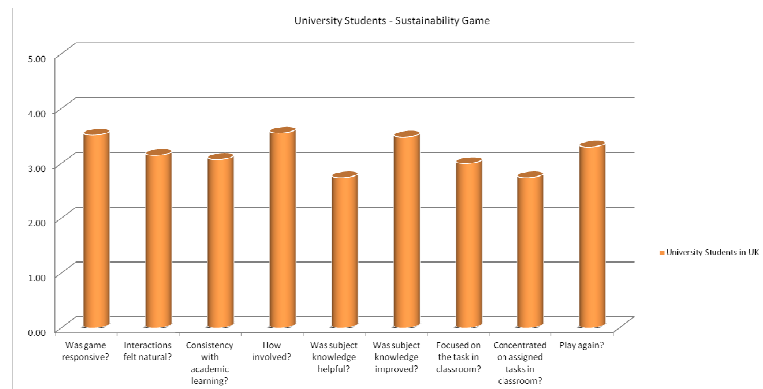

Figure 3. Students' beliefs of playing the sustainability game

The findings of the game evaluation have provided broad pointers to a wide range of considerations that should inform the practical implementation of the serious game in an academic setting. Against this background, the Sustainability Game seemed to be more pervasive for academic teaching and learning as it provided the foundations for actively constructing knowledge resulting from student's interaction with the virtual world. Moreover, the interaction with the virtual characters created the triggers to actively participate in completing the different quests as well as to identify and connect prior knowledge with new information that aid in creating meaningful learning. The Sustainability Game is a useful tool for accumulating, consolidating and extending knowledge in sustainability within an academic environment because:

It provides experiences, materials and sources of information for students to use directly from the virtual environment (Quest 1).

- Students may act in response to the different tasks required, showing the use of instruments necessary for completing a quest (Quests 1 and 2).

- Students may test their ideas or answer their questions through diverse ways of investigating and exploring a plethora of sustainability phenomena that take place in all quests.

- It facilitates integration of different learning quests, paths and objectives that have complementary tools which allow students to take different pathways towards solutions (All quests).
Since the Sustainability Game encompasses the use of technology and media to promote learning, we propose that it could efficiently be used in a 'blended learning' context, which blends different pedagogical approaches with tools and media for transforming the educational practice.

\section{AKNOWLEDGEMENT}

This work has been supported by the European Commission under the collaborative project ASPIS "Auditing the Sustainability of Public Spaces" funded by the European Commission under the Life Long Learning Programme KA3 Multilateral Project, Grant Agreement 2009-11805. Also this work has been supported by FP7 Grants from MAGELLAN project with grant agreement number 611526

\section{REFERENCES}

[1] E. Commission, "Commission proposes strategy to improve the environment in Europe's cities," Brussels. Available at: http://europa.eu/rapid/press-release_IP-06-34_en.htm [last accessed 11 April 2013]2006

[2] CABE, "What makes an eco-town?," London. Available at: http://www.oneplanetcommunities.org/wpcontent/uploads/2010/03/What-makes-an-eco-town-2008.pdf [Last accessed 5 April 2013]2008.

[3] L. Galarneau, Zibit, M, "Online games for 21st century skills. Games and simulations in online learning," Research and development frameworks, vol. 59-88, 2007.

[4] K. Schrier, "Using augmented reality games to teach 21 st century skills," in SIGGRAPH 2006 Educators Program. , ed: ACM, 2006, p. 15 .

[5] L. Johnson, Adams, L., Cummins, M, Estrada, V, Freeman, A, Ludgate, H, "NMC Horizon Report: 2013 Higher Education Edition ", Austin Texas Available at: http://www.nmc.org/pdf/2013-horizonreport-HE.pdf2013.

[6] M. Zyda, "From visual simulation to virtual rality to games," Computer, vol. 38, pp. 25-32 doi:10.1109/MC.2005.297, 2005.

[7] D. Ferreira, Palhares, P., Silva, J, "A perspective on games and patterns," in New pedagogical approaches in game enhanced learning: Curriculum integration, S. de Freitas, Ott, M., Popescu, M., Stanescu, I, Ed., ed Hershey PA: IGI Global, 2013, pp. 60-80.

[8] W. H. Huang, Huang, W.Y., Tschopp, J, "Sustaining iterative game playing processes in DGBL: the relationship between motivational processing and outcome processing," Computers \& Education, vol. 55, pp. 789-797, 2010

[9] S. Schaffer, Squirre, K., Halverson, R., Gee, J, "Video games and the future of learning," Available at: http://www.academiccolab.org/resources/gappspaper1.pdf 2004.

[10] T. M. Connolly, E. A. Boyle, E. MacArthur, T. Hainey, and J. M Boyle, "A systematic literature review of empirical evidence on computer games and serious games," Computers \& Education, vol. 59, pp. 661-686, 2012

[11] T. Hess and G. Gunter, "Serious game-based and nongame-based online courses: Learning experiences and outcomes," British Journal of Educational Technology, vol. 44, pp. 372-385, 2013.

[12] C. Obikwelu and J. C. Read, "The Serious Game Constructivist Framework for Children's Learning," Procedia Computer Science, vol. 15, pp. 32-37, 2012.

[13] S. de Freitas, Oliver, M, "A four dimsensional framework for the evaluation and assessment of educational games," Computer Assisted Learning Conference, 2005.

[14] G. J. Hwang, Sung, H.Y., Hung, C.M., Huang, I, "Development of a personalized educational computer game based on students' learning styles," Educational Technology Research \& Development, vol. 60, pp. 623-638, 2012. 